\title{
Pengaruh Perawatan Payudara terhadap Kelancaran Asi pada Ibu Nifas di RSUD Syeh Yusuf Kabupaten Gowa
}

\author{
Sitti Rahmatia ${ }^{*}$, Harliani²$^{2}$,Muhammad Basri ${ }^{3}$ \\ 1*. Poltekkes Kemenkes Makassar, Jl. Menumen Emmy Saelan III Tidung, Kota Makassar, Indonesia, 90222 \\ 2. Poltekkes Kemenkes Makassar, Jl. Menumen Emmy Saelan III Tidung, Kota Makassar, Indonesia, 90222 \\ 3. Poltekkes Kemenkes Makassar, Jl. Menumen Emmy Saelan III Tidung, Kota Makassar, Indonesia, 90222 \\ *e-mail: rahmatiahakp@gmail.com
}

(Received : 26-06-2019; Reviewed : 20-08-2019; Accepted : 24-08-2019)

\begin{abstract}
Breast care is a way of showing directly to postpartum mothers about how to care for the breast through giving stimulation to the breast muscles to facilitate breastfeeding. The purpose of this study was to find out the smoothness of breastfeeding for postpartum mothers after breast care. This study was a quasi-experimental study with a pre-test and post-test approach. 15 people in the control group. This study uses an observation sheet. The results of this study were processed using the Wilcoxon test with standard values $p<0.05$.The results of this study indicate that for the experimental group there was an effect of breast care on the smoothness of breast milk in postpartum mothers with a value of $p=0,000$. While for the control group $p=0.083$. This shows that in the control group that was not given breast care did not provide significant results. The conclusion of this study is that there is an effect of breast care on the smoothness of breast milk in postpartum mothers. Suggestions that can be given especially for the Lancirang Community Health Center so that breast care can be given continuously and can achieve exclusive breastfeeding.
\end{abstract}

Keywords: Breast Care, Smooth Breastfeeding

\begin{abstract}
Abstrak
Perawatan payudara adalah suatu cara memperlihatkan secara langsung pada ibu nifas tentang cara perawatan payudara melalui pemberian rangsangan pada otot-otot payudara untuk memperlancar ASI. Tujuan penelitian ini adalah untuk mengetahui kelancaran ASI ibu nifas setelah diberikan perawatan payudara.Penelitian ini merupakan penelitian Quasi eksperimen dengan pendekatan pre test dan post test, sampel dalam penelitian ini adalah ibu nifas hari pertama di wilayah kerja Puskesmas Lancirang yang berjumlah 15 orang kelompok eksperimen dan 15 orang kelompok kontrol. Penelitian ini menggunakan lembar observasi. Hasil penelitian ini diolah dengan menggunakan uji Wilcoxon dengan nilai standar $p<0,05$. Hasil penelitian ini menunjukkan bahwa untuk kelompok eksperimen ada pengaruh perawatan payudara terhadap kelancaran ASI pada ibu nifas dengan nilai $p=0,000$. Sedangkan untuk kelompok kontrol nilai $p=0,083$. Hal ini menunjukkan bahwa pada kelompok kontrol yang tidak diberikan perawatan payudara tidak memberikan hasil yang bermakna.Adapun kesimpulan dari penelitian ini adalah bahwa ada pengaruh perawatan payudara terhadap kelancaran ASI pada ibu nifas. Saran yang dapat diberikan khususnya untuk Puskesmas Lancirang agar perawatan payudara diberikan secara berkesinambungandemi tercapainya pemberian ASI eksklusif.
\end{abstract}

Kata Kunci : Perawatan Payudara, Kelancaran ASI 


\section{Pendahuluan}

Peningkatan pemberian ASI perlu dilakukan dalam upaya peningkatan kesehatan bagi bayi dan ibu, upaya tersebut dapat dilakukan anatara lain dengan cara pemberian ASI dini (Kepmenkes, 2002). Pemerintah telah berupaya dalam mensosialisasikan pemberian ASI termasuk ASI dini. Hal ini terbukti dengan telah dicanangkan Gerakan Nasional Peningkatan Penggunaan Air Susu Ibu (GNPPASI) oleh Presiden RI pada peringatan Hari ibu tanggal 22 Desember 1990 yang bertemakan " Dengan ASI kaum ibu mempelopori peningkatan kualitas manusia Indonesia ". Pemberian ASI tanpa makanan lain khususnya pada enam bulan pertama setelah kelahiran disebut dengan menyusui secara eksklusif.. Selain itu, pemberian ASI minimal selama 6 bulan juga dapat menghindarkan bayi dari obesitas atau kelebihan berat badan karena ASI membantu menstabilkan pertumbuhan lemak bayi. (Wiji, 2013) .Dan dirumuskan dalam Garis-garis Besar Haluan Negara (GBHN) 1999/2004 dan Program Pembangunan Nasional (Propenas) mengamanatkan bahwa pembangunan diarahkan pada peningkatan mutu Sumber Daya Manusia (SDM).Modal dasar pembentukan manusia berkualitas tersebut dimulai sejak masa bayi dalam kandungan sampai masa pemberian Air Susu Ibu (ASI) sejakusia dini.

Salah satu pelayanan KIA yang masih perlu ditingkatkan adalah perawatan bagi ibu nifas, dalam hal ini yang berhubungan dengan perawatan payudara yang benar untuk kelancaran ASI, mengingat ASI memiliki manfaat yang besar bagi bayi dan ibu bila diberikan sesuai kebutuhan bayi. ASI ini mengandung zat gizi yang sesuai untuk bayi, mengandung protektif, dan mempunyai efek psikologis yang menguntungkan. Semua manfaat tersebut tidak akan diberikan bila ibu-ibu memberikan susu formula pada bayinya.

Selain itu, ditemukan pula fakta dalam masyarakat bahwa salah satu penyebab mengapa banyak ibu yang tidak mau menyusui anaknya adalah karena tidak terjadinya kelancaran ASI karena faktor ketidaktahuan ibu tentang bagaimana cara merawat payudara yang baik pre maupun post partum. Untuk itu, diperlukan tenaga kesehatan untuk memberikan penyuluhan-penyuluhan tentang ASI dan faktor-faktor yang terkait di dalamnya.

Berdasarkan data yang diperoleh di RSUD. Syeh Yusuf Kabupaten Gowa, bahwa jumlah ibu nifas selama periode Januari-Desember 2017 sebanyak 230 orang. Dan perawatan payudara ibu post partum jarang dilakukan oleh karena keterbatasan tenaga (Data RSUD. Syeh Yusuf, 2017).Olehnya itu peneliti tertarik untuk meneliti Pengaruh Perawatan Payudara Terhadap Peningkatan ASI Pada Ibu Nifas Di RSUD.Syeh Yusuf Kabupaten Gowa.

\section{Metode}

Penelitian ini merupakan penelitian lapangan yang dilaksanakan dengan pendekatan Quasi Eksperimen untuk meneliti kelancaran ASI pada ibu nifas di RSUD. Syeh Yusuf Kabupaten Gowa..Bentuk penelitian yang digunakan adalah Quasi Eksperimen dengan rancangan Non Equivalent Control Group.Penelitian ini telah dilaksanakan di RSUS. Syeh Yusuf Kabupaten Gowa. pada Bulan Mei sampai dengan Agustus 2018. Populasi dalam penelitian ini adalah semua ibu nifas.sampel dalam penelitian ini yakni sebanyak 30 orang ibu nifas. Dalam penelitian ini sampel yang digunakan ada dua kelompok yang terdiri dari 15 orang kelompok intervensi an 15 orang kelompok kontrol.Pemilihan sampel dilakukan secara purposive sampling.

a. Partus pervaginam

b. Bayinya lahir normal, cukup bulan dan berat badan yang normal.

c. Tidak menderita kelainan pada payudara, misalnya : mastitis, kelainan puting susu dll.

d. Ibu masa nifas hari 1 dan hari 2 dan keluarnya ASI belum lancar.

\section{Pengumpulan Data}

1. Data Primer

Pengumpulan data dengan menggunakan kuesioner tertutup . Penelitian ini menggunakan skala nominal dan Guttman. Skala pengukuran tipe ini, akan didapat jawaban yang tegas dan konsisten dengan memberikan jawaban yang tegas seperti jawaban dari pertanyaan/pernyataan: ya dan tidak, positif dan negatif, setuju dan tidak setuju, benar dan salah.

2. Data sekunder

Data sekunder adalah data yang digunakansebagai data pelengkap untuk data primer yang berhubungan dengan masalah yang akan diteliti, yaitu data-data yang diambil dari Di RSUDSyekh YusufGowa..

\section{Analisis Data}

Analisis data melalui analisis univariat dan bivariat dengan menggunakan Uji Chi Square dengan nilai $\alpha<$ 0,05 dengan tingkat kepercayaan $95 \%$. 


\section{Hasil}

1. Analisa Univariat

Tabel 1. Demografi Responden Berdasarkan Kelompok Umur Pada Ibu Nifas Di RSUD Syekh Yusuf Gowa

\begin{tabular}{lcc}
\hline Karakteristik & Frekuensi & Persentase (\%) \\
\hline Eksperimen & & \\
18-27 Tahun & 6 & 40 \\
28-37 Tahun & 9 & 60 \\
Eksperimen & & \\
18-27 Tahun & 8 & 53 \\
28-37 Tahun & 7 & 47 \\
\hline
\end{tabular}

Hasil penelitian menunjukkan bahwa untuk kelompok intervensi umur responden 18-27 tahun yaitu sebanyak 6 orang (40\%) sedangkan umur responden 28-37 tahun yaitu sebanyak 9 orang (60\%).Dan untuk kelompok kontrolumur 18-27 tahun sebanyak 8 orang (53\%) sedangkan umur 28-37 tahun sebanyak 7 orang $(47 \%)$.

2. Analisa bivariat

a. Analisa kelancaran ASI ibu nifas sebelum diberikan perlakuan perawatan payudarapada kelompok eksperimen dan kelompok kontrol.

Tabel 2. Kelancaran ASI Ibu Nifas Sebelum Diberikan Perawatan Payudara Pada Kelompok Eksperimen Dan Kelompok Kontrol Pada Ibu Di RSUD Syeh Yusuf Gowa

\begin{tabular}{lcccc}
\hline Kelancaran & \multicolumn{2}{c}{ Kelompok Eksperimen } & \multicolumn{2}{c}{ Kelompok Kontrol } \\
\cline { 2 - 5 } ASI & $\mathrm{n}$ & $\%$ & $\mathrm{n}$ & $\%$ \\
\hline Lancar & 0 & 0 & 0 & 0 \\
Tidak Lancar & 15 & 100 & 15 & 100 \\
\hline \multicolumn{1}{c}{ Total } & 15 & 100 & 15 & 100 \\
\hline
\end{tabular}

Tabel 2 Menunjukkan bahwa kelancaran ASI sebelum diberikan perawatan payudara pada kelompok eksperimen terdapat 15 orang (100\%) yang tidak lancar ASInya. Sedangkan pada kelompok kontrol terdapat 15 orang $(100 \%)$ yang tidak lancar ASInya.

b. Analisa kelancaran ASI ibu Nifas setelah diberikan perlakuan perawatan payudarapada kelompok eksperimen dan kelompok kontrol.

Tabel 3. Kelancaran ASI Ibu Nifas Sebelum Diberikan Perawatan Payudara Pada Kelompok Eksperimen Dan Kelompok Kontrol Pada Ibu Di RSUD Syeh Yusuf Gowa

\begin{tabular}{lcccc}
\hline Kelancaran & \multicolumn{2}{c}{ Kelompok Eksperimen } & \multicolumn{2}{c}{ Kelompok Kontrol } \\
\cline { 2 - 5 } ASI & $\mathrm{n}$ & $\%$ & $\mathrm{n}$ & $\%$ \\
\hline Lancar & 15 & 100 & 10 & 67 \\
Tidak Lancar & 0 & 0 & 5 & 33 \\
\hline \multicolumn{1}{c}{ Total } & 15 & 100 & 15 & 100 \\
\hline
\end{tabular}

Tabel 3 menunjukkan bahwa kelancaran ASI setelah diberikan perawatan payudara pada kelompok eksperimen terdapat 15 orang (100\%) yang ASInya lancar. Sedangkan pada kelompok kontrol terdapat 10 orang $(67 \%)$ yang ASInya lancar dan 5 orang (33\%) yang ASInya tidak lancar.

c. Analisa pengaruh perawatan payudara terhadap kelancaran ASI ibu nifas pada kelompok eksperimen.

Tabel 4. Pengaruh Perawatan Payudara Terhadap Kelancaran Asi Ibu Nifas Pada Kelompok Eksperimen di RSUD Syeh Yusuf Gowa

\begin{tabular}{lcccc}
\hline Kelancaran & \multicolumn{2}{c}{ Kelompok Eksperimen } & \multicolumn{2}{c}{ Kelompok Kontrol } \\
\cline { 2 - 5 } ASI & $\mathrm{n}$ & $\%$ & $\mathrm{n}$ & $\%$ \\
\hline Lancar & 0 & 0 & 15 & 100 \\
Tidak Lancar & 15 & 100 & 0 & 100 \\
\hline \multicolumn{1}{c}{ Total } & 15 & 100 & 15 & 100 \\
\hline \multicolumn{5}{c}{$p=0,000$} \\
\hline
\end{tabular}


Tabel 4.menunjukkan bahwa untuk responden kelompok eksperimen atau kelompok yang diberikan perawatan payudara mengalami perubahan kelancaran ASI. Setelah dilakukan uji statistik maka didapatkan jumlah responden yang mengalami perubahan kelancaran ASI sebesar 100\% (15 orang). Sebelum di berikan perawatan payudara semua responden ASInya tidak lancar. Tetapi setelah diberikan perawatan payudara semua responden ASInya lancar.

Hasil uji wilcoxon didapatkan nilai $p=0,000$ lebih kecil daripada nilai standar $\alpha 0,05$ yang berarti ada pengaruhperawatan payudara terhadap kelancaran ASI pada ibu nifas.

d. Analisa pengaruh perawatan payudara terhadap kelancaran ASI ibu nifas pada kelompok kontrol.

Tabel 5. Pengaruh Perawatan Payudara Terhadap Kelancaran ASI Ibu NifasPada Kelompok Kontrol Di RSUD. Syeh Yusuf Gowa

\begin{tabular}{|c|c|c|c|c|}
\hline \multirow{2}{*}{$\begin{array}{l}\text { Kelancaran } \\
\text { ASI }\end{array}$} & \multicolumn{2}{|c|}{ Kelompok Eksperimen } & \multicolumn{2}{|c|}{ Kelompok Kontrol } \\
\hline & $\mathrm{n}$ & $\%$ & $\mathrm{n}$ & $\%$ \\
\hline Lancar & 0 & 0 & 3 & 20 \\
\hline Tidak Lancar & 15 & 100 & 12 & 80 \\
\hline Total & 15 & 100 & 15 & 100 \\
\hline \multicolumn{5}{|c|}{$p=0,000$} \\
\hline
\end{tabular}

Tabel 5.menunjukkan bahwa untuk responden kelompok kontrol atau kelompok yang tidak diberikan perawatan payudara sama sekali tidak mengalami perubahan kelancaran ASI hasil pre test sama dengan hasil post test. Setelah dilakukan uji statistik didapatkan jumlah responden yang ASInya lancar sebanyak 3 orang (20\%), dan 12 orang (80\%) ASInya tidak lancar. Pada kelompok kontrol ini tidak ada perubahan tingkat pengetahuan antara pre test dan post test.

Hasil uji wilcoxon didapatkan nilai $p=0,083$ lebih besar daripada nilai standar $\alpha 0,05$ yang berarti bahwa pada kelompok kontrol yang tidak diberikan perawatan payudara tidak memberikan hasil yang bermakna.

e. Distribusi pengaruh perawatan payudara terhadap kelancaran ASI ibu nifas pada kelompok eksperimen dan kelompok kontrol.

Tabel 6. Distribusi Pengaruh Perawatan Payudara Terhadap Kelancaran ASI Ibu Nifas Pada Kelompok Eksperimen Dan Kelompok Kontrol Di RSUD Syeh Yusuf Gowa

\begin{tabular}{|c|c|c|c|c|c|}
\hline Hasil & Tanda Jenjang & $\mathbf{n}$ & $\%$ & $\mathbf{Z}$ & $\begin{array}{l}\text { Asymp.Sig } \\
\text { (2-Tailed) }\end{array}$ \\
\hline Pre-Post Tes & Rangking Negatif & 0 & 0 & & \\
\hline Kelanca & Rangking Positif & 15 & 100 & 3,873 & 0,000 \\
\hline ran ASI & Tetap & 0 & & & \\
\hline \multicolumn{2}{|c|}{ Total Kelompok Eksperimen } & 15 & 100 & & \\
\hline \multirow{3}{*}{$\begin{array}{c}\text { Kontrol perawat-an } \\
\text { payuda- } \\
\text { Ra }\end{array}$} & Rangking Negatif & 0 & 0 & & \\
\hline & Rangking Positif & 3 & 20 & 1.732 & 0,083 \\
\hline & Tetap & 12 & 80 & & \\
\hline \multicolumn{2}{|c|}{ Total Kelompok Kontrol } & 15 & 100 & & \\
\hline
\end{tabular}

Tabel 6. menunjukkan bahwa untuk kelompok eksperimen dengan jumlah 15 responden yang menunjukkan nilai post test < pretes (Rangkin negatif) $0 \%$, nilai post test > pre test (rangking positif) 15 orang atau $100 \%$, dan nilai posttest $=$ pretest berjumlah 0 orang atau $0 \%$. Dari hasil uji rangking bertanda Wilcoxon dengan menggunakan statistic Z, didapatkan nilai untuk kelompok eksperimen $-3,873$ dengan taraf kesalahan 0,000 dan tingkat kepercayaan 95\%. Sedangkan pada kelompok kontrol dengan jumlah 15 responden yang menunjukkan nilai post test < pre test (rangking negatif) 0 atau $0 \%$, nilai posttest $>$ pretest (rangking positif) 3 atau $20 \%$ dan post test $=$ pre test 12 orang $(80 \%)$. Pada tabel 4.6 terlihat bahwa kelompok kontrol, nilai $\mathrm{Z}=-1,732$ dengan taraf kesalahan 0,083 dengan tingkat kepercayaan $95 \%$.

Dengan demikian nilai kapasitas uji dua pihak (2 Tailed), terlihat bahwa pada kelompok eksperimen nilai $\mathrm{p}=0,000$ dan kelompok kontrol $\mathrm{p}=0,083$ berarti nilai $\mathrm{p}$ untuk kelompok eksperimen < daripada nilai p kelompok kontrol. Sehingga perbandingan nilai ini menunjukkan bahwa kelompok eksperimen yang diberikan perlakuan perawatan payudara memberikan hasil yang bermakna. Jadi ada pengaruh perawatan payudara terhadap kelancaran ASI pada ibu nifas. 


\section{Pembahasan}

Berdasarkan hasil penyajian data di atas dapat diperoleh beberapa informasi mengenai variabel independen terhadap variabel dependen yang akan dibahas lebih lanjut dibawah ini :

Sebelum diberikan perawatan payudara diperoleh bahwa untuk kelompok eksperimen terdapat 15 orang (100\%) yang tidak lancar ASInya. Sedangkan pada kelompok kontrol terdapat 15 orang (100\%) yang tidak lancar ASInya.

Setelah diberikan perawatan payudara diperoleh bahwa untuk kelompok eksperimen ada 15 orang (100\%) yang ASInya lancar. Hasil uji wilcoxon didapatkan nilai $\mathrm{p}=0,000$ lebih kecil daripada nilai standar $\alpha=0,05$ yang berarti ada hubungan antara perawatan payudara terhadap kelancaran ASI ibu nifas.Dengan demikian kelancaran ASI untuk kelompok eksperimen bertambah setelah diberikan perawatan payudara.

Sedangkan untuk kelompok kontrol jumlah responden 15 orang terdapat 3 orang (20\%) yang ASInya lancar dan 12 orang (80\%) yang ASInya tidak lancar.Hasil uji wilcoxon didapatkan nilai $\mathrm{p}=0,083$ lebih besar daripada nilai standar $\alpha=0,05$ yang berarti bahwa pada kelompok kontrol diberikan perawatan payudara tidak memberikan hasil yang bermakna. Dengan demikian untuk kelompok kontrol sama sekali tidak mengalami perubahan kelancaran ASI, karena untuk kelompok ini tidak diberikan perlakuan.

Dari hasil pengolahan data didapatkan bahwa ada pengaruh perawatan payudara terhadap kelancaran ASI pada ibu nifas dengan nilai $\mathrm{p}=0,000$ lebih kecil daripada nilai standar $\alpha=0,05$ yang berarti bahwa pada kelompok eksperimen memberikan hasil yang bermakna.

Sesuai dengan penelitian sebelumnya yang dilakukan oleh Rini Mulyani (2009) bahwa perawatan payudara merupakan usaha untuk memperlancar aliran ASI dan mencegah masalah-masalah yang mungkin muncul pada saat menyusui. Hasil penelitian ini membuktikan bahwa dengan perawatan payudara dapat meningkatkan produksi ASI.

Maria Beatrix Tyfani,(2017), mengkaji 32 orang ibu post partum, tentang hubungan perawatan payudara terhadap kelancaran ASI pada ibu post partum di Kelurahan Tlogomas Kecamatan Lowokwaru Kota Malang, memperlihatkan ada hubungan yang signifikan antara pelaksanaan peraatan payudara dengan kelancaran ASI ibu post partum. Berdasarkan teori menurut Sastropoerto (2013) bahwa dalam pelaksanaan suatu rencana harus tercapai dimana perlu diperhatikan penyusunan yang baik dan jelas sedangkan kelancaran juga mempunyai kaitan yang sama dengan pelaksanaan dimana rencana atau kegiatan tersebut harus tercapai. Jadi dengan melakukan perawatan payudara yang baik maka tercapai kelancaran ASI yang baik.Dengan demikian menurut peneliti pelaksanaan perawatan payudara yang baik yang dilakukan seorang ibu maka akan mempengaruhi kelancaran ASI

\section{Kesimpulan}

1. Sebelum diberikan intervensi yaitu perawatan payudara, ASI tidak lancar

2. Setelah diberikan perlakuan yaitu perawatan payudara ASI menjadi lancar dengan memberikan hasil yang bermakna dengan nilai $p=0,000$.

3. Terdapat pengaruh perawatan payudara terhadap kelancaran ASI dengan nilai $p=0,000$ pada kelompok eksperimen, dan nilai $p=0,083$ pada kelompok kontrol.

\section{Saran}

1. Perawatan payudara pada ibu nifas perlu dilakukan secara berkesinambungan, karena merupakan solusi yang sederhana namun dipandang efektif untuk meningkatkan kelancaran ASI demi tercapainya pemberian ASI ekslusif.

2. Sebagai masukan bagi tenaga perawat dan bidan untuk menambah pengetahuan dan wawasan dalam memberikan perawatan payudara.

3. Bagi peneliti selanjutnya yang berminat untuk meneliti permasalahan tentang perawatan payudara hendaknya menggunakan sampel yang lebih banyak

\section{Referensi}

Bahiyatun. 2009. Buku Ajar Asuhan Kebidanan Nifas Normal. EGC, Jakarta.

Cunningham. 2006.Obstetri Williams. Vol, 1.Edisi 21. EGC, Jakarta.

Harun Yahya. 2009. Manfaat ASI Dan ASIeksklusif (http://www.harunyahya.com, diakses 17 Maret 2010. 
Hidayat Alimul Aziz. 2007. Metode Penelitian Keperawatan dan Teknik Analisa Data . Salemba Medica, Jakarta.

Farrer, Helen. 2001. Perawatan Maternitas. Edisi 2.EGC. Jakarta.

Luwia, S, Mellissa. 2003. Problematik \& Perawatan Payudara Kesehatan dan Kecantikan. Kawan Pustaka. Jakarta.

Nanix. 2009. Perawatan Payudara Pada Ibu Hamil Dan Ibu Nifas. (http://www.kesehatan.com, diakses 9 Maret 2010).

Notoatmodjo, Dr. Soekidjo. 2005. Metodologi Penelitian Kesehatan. PT. Rineka Cipta, Jakarta.

Nursalam. 2003. Konsep Dan Penerapan Metodologi Penelitian Ilmu Keperawatan. Salemba Medika, Jakarta.

Perkumpulan Perinatologi Indonesia, 2007, Manajemen Laktasi : Menuju Persalinan Aman dan Bayi Lahir Sehat.

Puskesmas Lancirang. 2010. Medical Record. Puskesmas Lancirang Sidrap.

Puskesmas Lancirang. 2009. Profil Kesehatan Masyarakat. Sidrap

Ratihrochmat, 2008, Perawatan Masa Nifas, (http://wordpress.com, diakses 9 maret 2010).

Rini Mulyani. 2009. Pengaruh Metode Demontrasi Perawatan Payudara Terhadap Kelancaran Pengeluaran

ASI Pada Ibu Nifas Di Ruang Nifas RS.Siti Fatimah Makassar.Skripsi tidak diterbitkan.Makassar : STIKES Nani Hasanuddin.

Saleha,Sitti. 2009. Asuhan Kebidanan Pada Masa Nifas. Salemba Medika, Jakarta.

Samhadi. 2008. Anatomi dan Fisiologi Payudara. (http://www.lusa.web.id, diakses 9 Maret 2010).

Saryono. 2008. Perawatan Payudara. Mitra Cendekia. Jogjakarta.

Suherni. 2009. Perawatan Masa Nifas. Fitramaya.Yogyakarta.

Tim Penyusun. 2010. Pedoman Penulisan Skripsi. Edisi 6. Stikes Nani Hasanuddin, Makassar.

Wiknjosastro, Hanifa. 2007. Ilmu Kebidanan. Edisi 3. Yayasan Bina Pustaka Sarwono Prawirohardjo. Jakarta 